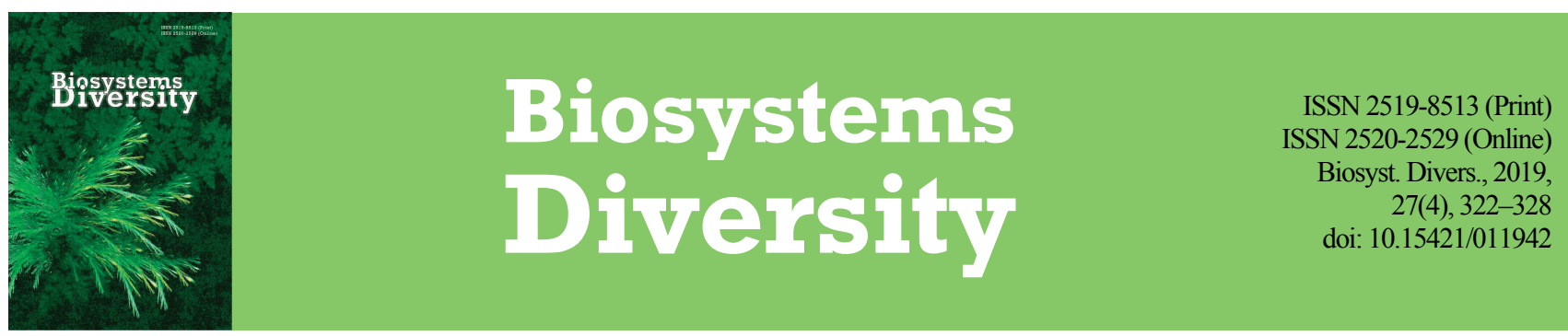

\title{
Temperature effect on the temporal dynamic of terrestrial invertebrates in technosols formed after reclamation at a post-mining site in Ukrainian steppe drylands
}

\author{
O. Y. Pakhomov*, O. M. Kunakh*, A. V. Babchenko**, \\ M. P. Fedushko***, N. I. Demchuk****, L. S. Bezuhla****, O. S. Tkachenko**** \\ *Oles Honchar Dnipro National University, Dnipro, Ukraine \\ **Ukrainian State University of Chemical Technology, Dnipro, Ukraine \\ ***Bogdan Khmelnitsky Melitopol State Pedagogical University, Melitopol, Ukraine \\ ****Dnipro State Agrarian and Economic University, Dnipro, Ukraine
}

Article info

Received 15.10.2019

Received in revised form 17.11.2019

Accepted 18.11.2019

Oles Honchar Dnipro National

University, Gagarin av., 72,

Dnipro, 49010, Ukraine.

Tel.: +38-098-858-23-79.

E-mail:kunah_olga@ukr.net

Ukrainian State University

of Chemical Technology,

Gagarin av., 8, Dnipro,

49005, Ukraine E-mail: linean-

na83@gmail.com

Bogdan Khmelnitsky Melitopol State Pedagogical University

Hetmanska st., 20, Melitopol

72318, Ukraine. E-mail: marinafedushko@gmail.com

Dnipro State Agrarian and Economic University Sergey Yefremov st. 25 ,

Dnipro, 49600 Utraine.

E-mail:natademchyk@gmail.com

Pakhomov, O. Y., Kunakh, O. M., Babchenko, A. V., Fedushko, M. P., Demchuk, N. I., Bezuhla, L. S., \& Tkachenko, O. S. (2019). Temperature effect on the temporal dynamic of terrestrial invertebrates in technosols formed after reclamation at a post-mining site in Ukrainian steppe drylands. Biosystems Diversity, 27(4), 322-328. doi:10.15421/011942

\begin{abstract}
The research was carried out at the Research Centre of the Dnipro State Agrarian and Economic University in Pokrov city. Sampling was carried out in 2013-2015 on a variant of artificial soil (technosols) formed on loess-like loam, red-brown clay, green-grey clay, technological mixture of rocks, and also formed on loess-like loam with a humus-rich $70 \mathrm{~cm}$ top soil layer. To investigate the spatiotemporal variation in the abundance, species richness and species composition of invertebrate assemblages within the experimental polygon, the animals were sampled using pitfall traps. In total, 60 pitfall traps were operated simultaneously during each sampling period. Each year the pitfalls were emptied 26 times every 7-9 days. Invertebrates (Arthropoda and Mollusca) of 6 classes, 13 orders, 50 families and 202 species or parataxonomic units were recorded. Diplopoda was most abundant taxonomic group, though it was represented by only one species Rossiulus kessleri (Lohmander, 1927). Coleoptera and Araneae were the most numerous taxonomic groups. Readily available water for plants, precipitation, wind speed, atmospheric temperature (daily minimum, daily maximum, daily mean), atmospheric humidity and atmospheric pressure were used as environmental predictors. Two dimension geographic coordinates of the sampling locations were used to generate a set of orthogonal eigenvector-based spatial variables. Time series of sampling dates were used to generate a set of orthogonal eigenvector-based temporal variables. The moisture content in the technosols was revealed to be the most important factor determining the temporal dynamics of the terrestrial invertebrate community in conditions of semi-arid climate and the ecosystem which formed as a result of the reclamation process. Following soil moisture, the factor most strongly affecting invertebrates in the technosols was temperature. From the total set of the invertebrates, two relatively homogeneous species groups in terms of thermal preferences were extracted: the microtemperature and mesotemperature groups. The microtemperature species are more tolerant to the thermal factor, and the mesotemperature species are more sensitive. The Huisman-OlffFresco approach expanded by Jansen-Oksanen provides a wide set of ecologically relevant models which are able to explain species response. The species response to temperature is affected by a complex of other environmental, temporal and spatial factors. The effect of other factors on the species response must be previously extracted to find real estimations of the species temperature optima and tolerance. The approaches to solving this problem may be the object of future investigation.
\end{abstract}

Keywords: species response; temperature; niche; tolerance; reclamation; gradient; temporal dynamic.

\section{Introduction}

Niche theory is a powerful approach to understanding mechanisms underlying the temporal and spatial dynamic of populations or communities (Schoener, 1989; Tokeshi, 1999). Niche theory predicts that the distribution of species is forced by the differences between species optima and environmental factors (Hutchinson, 1957). The ecological niche may be considered in the context of the two dimensions: Grinnellian and Eltonian (Soberon, 2007). The Grinnellian niche takes into account the importance of a given set of resources for the survival of a species (Devictor et al., 2010; Sokolov \& Zhukov 2017). The Grinnellian niche is considered in two ways: on the one hand as a complex of the habitat conditions and on the other hand as behavioural adaptations allowing organisms to persist and produce offspring (Grinnell, 1917). The Eltonian niche is concentrated not only on the consideration of species response to impact of environment but on the consideration of species impact within the environment. The niche reflects the place of a species in the biotic environment, its relations to food and enemies (Elton, 1927).
The terrestrial macroinvertebrate communities of arid and semi-arid ecosystems are represented by insects, spiders, mollusks, and myriapods (Pakhomov et al., 2008; Gerlach et al., 2013; Brygadyrenko, 2016). Among insects, the ground-dwelling beetles (especially Carabidae, Scarabaeidae, and Tenebrionidae) form the most considerable component of the community in arid ecosystems (Konstantinov et al., 2009). Spiders are the dominant predators and a species-rich group in most terrestrial ecosystems (Wise, 1993; Rushton \& Eyre, 1992). Saprophagous macroarthropods provide a key role in organic matter turnover within most ecosystems (Paoletti et al., 2007). Millipedes, woodlice and other saprophagous macroarthropods are classified as litter transformers (Lavelle et al., 1997) and represent key regulators of plant litter decomposition within ecosystems (David \& Handa, 2010). The sensitivity of saprophagous macroarthropods to environmental impacts makes them invaluable bioindicators (Paoletti \& Hassall, 1999; Souty-Grosset et al., 2005). Humidity and moisture affect activity and distribution of terrestrial isopods (Warburg et al., 1984). Climatic factors, predation and parasitism are the frequent drivers of Isopoda population dynamic (Warburg et al., 1984). Shrub cover and herbaceous species richness were shown to be the best drivers of detritivore 
and herbivore beetle community species composition. For predator species composition, shrub height and cover were found to be the best predictors (Liu et al., 2016). The herbivorous and predatory arthropods' range characteristics were shown to be correlated with both diet breadth (Brandle et al., 2002; Beck \& Kitching, 2007) and habitat breadth (Brandle et al., 2003). The distribution and abundance of spiders depends on three niche axes: wind, moisture and temperature (Wise, 1993). Spider species occurrence is frequently related to factors such as vegetation structure, soil moisture, disturbance and management regime (Marc et al., 1999; Bonte et al., 2002). The importance of the effect of habitat landscape properties on spider assemblages was reported (Gallé et al., 2011). Four clearly separable spider species groups (salt meadows, dunes, meadows and floodplain forests) along a soil salinity and moisture gradient were extracted (Buchholz, 2009). It is also important to note that several studies failed to find convincing correlations between the environment and the occurrence of spiders (Mallis \& Hurd, 2005). The spatial distribution of carabids around arable field-woodlot boundaries was explored using logistic curves with the Huismann-OlfFresco models (Knapp et al., 2019). The species - specific effects of shrub cover on Arthropoda animal groups that act as indicators of degradation were revealed due to focusing on species niche breadths and optima (Hering et al., 2019). Coexistence mechanisms at multiple scales in insect assemblages were explored with Huisman-Olff-Fresco models (Laporta \& Sallum, 2014). The vegetation and vegetation-soil interactions are important determinants of beetle community assemblies. The vegetation changes had stronger effects on the functional group composition than changes in the soil did (Liu et al., 2016).

Deep underground hard-rock mining has a considerable impact on the landscape, transforming original habitats and leaving landscapes in altered states (Szczepanska \& Twardowska, 1999; Hodecek et al., 2015; Klimkina et al., 2018; Yorkina et al., 2019). The landscape transformation due to open-pit coal mining causes major changes in terrain structures, waterways, microclimates, land uses, and living organism communities (Sklenicka et al., 2004; Hendrychova et al., 2011; Yorkina et al., 2018; Zadorozhnaya et al., 2018). The technical and biological reclamation phase is essential for managing a disturbed landscape (Hildmann \& Wunsche, 1996; Rehor et al., 2006; Hodecek et al., 2016). The technical phase of the reclamation processes is a significant disturbance that slows down the successional rate of beetle communities (Hodecek et al., 2015).

In this study, we applied different approaches to assess temperature optima and tolerance of the ecological niche temporal projection of the terrestrial invertebrates within an experimental polygon created to investigate the dynamic of reclamation processes after deep underground hard-rock mining in the Ukrainian steppe drylands. Our main objective here was to determine whether the temperature variability affects the temporal dynamic of the terrestrial invertebrates and to find properties of the species response curves to temperature.

\section{Materials and methods}

The research was carried out at the Research Centre of the Dnipro State Agrarian and Economic University in Pokrov city. Sampling was carried out on a variant of artificial soil (technosols) formed on loesslike loam, red-brown clay, green-grey clay, technological mixture of the rocks, and formed on loess-like loam with a humus-rich $70 \mathrm{~cm}$ top soil layer (the geographic coordinates of the experimental polygon are $47^{\circ} 38^{\prime} 55.24^{\prime \prime N}$.L., $34^{\circ} 08^{\prime} 33.30^{\prime \prime}$ E.L.). The data set comprised 20 plots from five technosol types presented within the experimental polygon.

To investigate the temporal dynamic in the abundance, species richness and species composition of invertebrate communities within the experimental polygon, animals were sampled using pitfall traps. The term "activity-density" is employed in some studies as this value is affected not only by population density but also by animal movement activity (Knapp et al., 2019). We investigated seven invertebrate groups closely associated with the soil environment or aboveground vegetation strata: (1) mollusks (Mollusca: Gastropoda), (2) spiders (Chelicerata: Arachnida), (3) millipedes (Myriapoda: Diplopoda), (4) centipedes (Myriapoda: Chilopoda), (5) terrestrial isopods (Malacostraca: Isopoda:
Oniscidea); (6) insects (Tracheata: Insecta). In total, 60 pitfall traps were operated simultaneously during each sampling period. In each plot, three pitfalls were placed in a triangle of $3 \mathrm{~m}$ base (Desender et al., 1999; Pontegnie et al., 2005) and emptied each 7-9 days. In 2013 pitfalls were placed on April 9. The pitfalls were emptied 26 times each year. The exact sampling dates were as follows in 2013: April 15, April 22, April 30, May 7, May 14, May 21, May 28, June 4, June 11, June 18 , June 25, July 2, July 9, July 17, July 24, July 31, August 7, August 15, August 23, August 30, September 7, September 15, September 23, September 30, October 7, October 14. In 2014 pitfalls were placed on April 5. The exact sampling dates were as follows in 2014: April 13, April 20, April 28, May 5, May 13, May 21, May 30, June 8, June 17, June 24, July 1, July 8, July 17, July 25, August 1, August 9, August 18, August 26, September 4, September 11, September 18, September 26, October 5, October 12, October 19, October 27. In 2015 pitfalls were placed on April 6. The exact sampling dates were as follows in 2015: April 14, April 21, April 28, May 5, May 13, May 20, May 27, June 3, June 10, June 17, June 24, July 1, July 9, July 17, July 24, August 2, August 11, August 18, August 26, September 4, September 11, September 20, September 28, October 6, October 15, October 22. The pitfall traps were made of 1-litre glass cups $(10 \mathrm{~cm}$ in diameter) buried in the soil with the rim of the cup level with the soil surface. The cups were filled with $250 \mathrm{ml}$ of preservative fluid made from concentrated $\mathrm{NaCl}$ solution, which seems to be efficient for collecting invertebrates and is relatively non-toxic to non-target organisms. Traps were covered by roofs made of a polyethylene sheet to prevent flooding during heavy rain. Roofs were placed $5 \mathrm{~cm}$ above the openings of the cups using four long rods that penetrated the corners of the roofs.

Vascular plant species lists were compiled in 2015 for each site along with visual estimates of species cover using the nine-degree Braun-Blanquet scale (Westhoff \& van der Maarel, 1978). The projective cover of plant species was recorded at ground level. We were able to make species level identification for all sites. Based on geobotanical descriptions, phytoindicative assessment of soil thermal regime according to Didukh (2011) was made. Phytoindicational evaluation of environmental factors was performed by the ideal indicator method of $\mathrm{Bu}$ zuk (2017). The readily available water for plants (RAW, mm in $1 \mathrm{~m}$ soil layer), precipitation ( $\mathrm{mm})$, wind speed $(\mathrm{m} / \mathrm{s})$, atmospheric temperature (daily minimum, daily maximum, daily mean, ${ }^{\circ} \mathrm{C}$ ), atmospheric humidity (\%) and atmospheric pressure ( $\mathrm{gPa}$ ) were used as environmental predictors (Kunah et al., 2019).

Ecological structures and processes occur across multiple spatiotemporal scales (Nash et al., 2014). Ecological systems are hierarchically structured and may be decomposed into structural and process components (La Notte et al., 2017). These components can be defined over a range of spatial and temporal scales (Allen et al., 2014). The elucidation of the mechanisms underlying observed spatial and temporal patterns and different scale levels is a key to prediction and understanding to the development of principles of management (Levin, 1992). The importance of stochastic processes was found to be dependent on the size of the study area (Bonsall \& Hastings, 2004). The complexity has to be accounted for in order to model temporal patterns in time series (Baho et al., 2015). The principal coordinates of neighbour matrix method (PCNM) is an effective procedure able to identify temporal structures of varying scale in time data (Borcard \& Legendre, 2002; Borcard et al., 2004; Dray et al., 2006). The PCNM-based approach was developed in distance-based Moran's eigenvector maps (MEM) (Dray et al., 2006; Baho et al., 2015).

The two dimension geographic coordinates of sampling locations were used to generate a set of orthogonal eigenvector-based spatial variables (Spatial dbMEMs), each of them representing a pattern of particular scale within the extent of the sampling area. Likewise, but only, the one dimension time series of sampling dates were used to generate a set of orthogonal eigenvector-based temporal variables (Time dbMEMs), each of them representing a pattern of particular scale within the extent of the investigated time period (Borcard \& Legendre, 2002; Dray et al., 2012). The spatial and time dbMEMs-variables were used as spatial and temporal predictors of the species responses (Zhukov et al., 2019). 
The species abundances were used as the weights in calculating the ecological factor average (Šmilauer \& Lepš, 2014):

$$
W A=\frac{\sum_{i=\mathbf{1}}^{n} \text { Env }_{i} \times \text { Abund }_{i}}{\sum_{i=\mathbf{1}}^{n} \text { Abund }_{i}},
$$

where Envi is the value of environmental variable in the $\mathrm{i}$-th sample, and Abundi is the abundance of the species in the i-th sample.

The species tolerance which is presented by the width of the bellshaped curve can be calculated as the square root of the weighted mean of the squared differences between the species optimum and the actual value in the sample. The value is analogous to standard deviation (Šmilauer \& Lepš, 2014):

$$
S D=\sqrt{\frac{\sum_{i=\mathbf{1}}^{n}\left(E n v_{i}-W A\right)^{\mathbf{2}} \times \text { Abund }_{i}}{\sum_{i=\mathbf{1}}^{n} \text { Abund }_{i}}} .
$$

Generalized linear mixed models were used for modeling speciesenvironment relationships. This approach is useful in the case of the unimodal symmetric species response (Jamil \& ter Braak, 2013). In the environment $R$ the model can be fitted by (Oksanen, 2004):

$\bmod <-\operatorname{glm}\left(\mathrm{y} \sim \mathrm{x}+\mathrm{I}\left(\mathrm{x}^{\wedge} 2\right)\right.$, family=poisson $)$

$\mathrm{b}<-\operatorname{coef}(\mathrm{mod})$

$\mathrm{u}<--\mathrm{b}[2] / 2 / \mathrm{b}[3]$

$\mathrm{t}<-$ sqrt $(-1 / 2 / \mathrm{b}[3])$

where $\mathrm{y}-$ species response, $\mathrm{x}$ - environmental factor, $\mathrm{u}-$ species optimal value, $\mathrm{t}-$ species tolerance.

The use of symmetric Gaussian response functions in gradient analysis is not a universal approach due to systematic deviation of the real data from symmetric response (Austin, 1976, 1999, 2013; Austin et al., 1999). Huisman, Olff and Fresco (1993) hierarchical models (HOF) along with a symmetric response also include a skewed response. Two bimodal (skewed and symmetric) response shapes were included to cope with species that are restricted to gradient extremes due to competition (Jansen, Oksanen, 2013; Michaelis \& Diekmann, 2017). The Huisman-Olff-Fresco models expanded by Jansen-Oksanen (HOFJO) are ranked according to the increasing complexity of biological information contained (Huisman et al., 1993; Jansen \& Oksanen, 2013). Model I: no significant trend in space or time:

$$
y=M \frac{1}{1+e^{a}} .
$$

Model II: an increasing or decreasing trend where the maximum is equal to the upper bound $\mathrm{M}$ :

$$
y=M \frac{1}{1+e^{a+b x}} .
$$

Model III: an increasing or decreasing trend where the maximum is below the upper bound $\mathrm{M}$ :

$$
y=M \frac{1}{1+e^{a+b x}} \frac{1}{1+e^{c}} .
$$

Model IV: increase and decrease by the same rate - symmetrical response curve:

$$
y=M \frac{1}{1+e^{a+b x}} \frac{1}{1+e^{c-b x}} .
$$

Model V: increase and decrease by different rates - skewed response curve:

$$
y=M \frac{1}{1+e^{a+b x}} \frac{1}{1+e^{c+d x}} .
$$

Model VI: bimodal symmetric responses:

$$
y=M \frac{1}{1+e^{a+b x}} \frac{1}{1+e^{c+b(x-d)}}+\frac{1}{1+e^{a+b(x-d)}} \frac{1}{1+e^{c-b(x-d)}} .
$$

Model VII: bimodal skewed responses:

$$
y=M \frac{1}{1+e^{a+b x}} \frac{1}{1+e^{c+b(x-d)}}+L \frac{1}{1+e^{a+b(x-d)}} \frac{1}{1+e^{c-b(x-d)}} .
$$

where $y$ and $x$ are the response and the explanatory variable respectively, $a, b, c$ and $d$ the parameters to be estimated ( $b$ and $d$ have opposite signs), and $M-$ a constant which equals the maximal value which can be attained (for relative frequencies $M=1$, for percentages $M=100$ ), $L-$ a constant which equals the maximal value for minor extreme value.

Huisman-Olff-Fresco models were fitted in the R statistical program (v. 3.3.1) (R Developmental Core Team, 2019) using the package "eHOF" (Jansen \& Oksanen, 2013, version 3.2.2). The Akaike information criterion corrected for small data sets (AICc) was used (Burnham \& Anderson, 2002). Optimum value and relative species tolerance limits, or the Central Borders, were calculated as implemented in the eHOF package (Jansen \& Oksanen, 2013).
To analyze the spatiotemporal variation in the species composition of invertebrate assemblages, multivariate ordination techniques were applied. To decrease the dimension of community space, nonmetric multidimensional scaling (NMDS) was applied (Jansen \& Oksanen, 2013). For ecological data with many zeros, the Hellinger transformation is useful (Rao, 1995). In this regard, prior to analyses, species data were Hellinger-transformed (Legendre \& Gallagher, 2001). In our data there were no rare species represented by less than 7 sites; that is why all species were included in the analyses, resulting in a final dataset of 202 species or parataxonomic units. For the statistical analyses we used the appropriate procedures of Statistica (Version 5.5, StatSoft Inc.,

\begin{tabular}{|c|c|c|c|c|c|}
\hline Site & Technosols & $\begin{array}{l}\text { Species } \\
\text { number }\end{array}$ & $\begin{array}{l}\text { Thermal } \\
\text { climate } \\
\text { indicator } \\
\text { value }\end{array}$ & $\begin{array}{l}\text { Phytoindicator } \\
\text { estimation of the } \\
\text { radiation balance, } \\
{\mathrm{MJ} \bullet \mathrm{m}^{2} \cdot \text { year }^{-1}}^{-1}\end{array}$ & $\begin{array}{l}\text { The favourable eco- } \\
\text { groups by the relation } \\
\text { of plant species to } \\
\text { thermoregime* }\end{array}$ \\
\hline 1 & \multirow{5}{*}{$\begin{array}{l}\text { Loess-like } \\
\text { loam }\end{array}$} & 23 & 10.4 & 2175.1 & sub-mesotherms \\
\hline 2 & & 17 & 11.1 & 2327.5 & mesotherms \\
\hline 3 & & 21 & 11.1 & 2333.9 & mesotherms \\
\hline 4 & & 15 & 10.6 & 2217.1 & sub-mesotherms \\
\hline 5 & & 20 & 10.9 & 2281.9 & sub-mesotherms \\
\hline 6 & \multirow{5}{*}{$\begin{array}{l}\text { Red-brown } \\
\text { clay }\end{array}$} & 26 & 11.0 & 2309.5 & mesotherms \\
\hline 7 & & 11 & 9.8 & 2049.5 & sub-mesotherms \\
\hline 8 & & 31 & 9.6 & 2001.8 & sub-mesotherms \\
\hline 9 & & 30 & 10.1 & 2107.9 & sub-mesotherms \\
\hline 10 & & 13 & 10.9 & 2274.4 & sub-mesotherms \\
\hline 11 & Green-grey & 23 & 10.6 & 2224.0 & sub-mesotherms \\
\hline 12 & clay & 23 & 10.5 & 2208.3 & sub-mesotherms \\
\hline 13 & Humus-rich & 13 & 10.0 & 2083.0 & sub-mesotherms \\
\hline 14 & $70 \mathrm{~cm}$ top soil & 16 & 9.9 & 2070.5 & sub-mesotherms \\
\hline 15 & layer formed on & 26 & 10.3 & 2154.0 & sub-mesotherms \\
\hline 16 & loess-like loam & 16 & 10.6 & 2222.6 & sub-mesotherms \\
\hline 17 & & 15 & 9.5 & 1985.6 & sub-mesotherms \\
\hline 18 & Technological & 16 & 8.3 & 1729.2 & sub-microtherms \\
\hline 19 & mixture of rocks & 19 & 10.2 & 2128.9 & sub-mesotherms \\
\hline 20 & & 20 & 9.7 & 2024.3 & sub-mesotherms \\
\hline
\end{tabular}
www.statsoft.com) or R (version 3.5.2; R Core Team, 2018).

\section{Results}

In total 35 species of herbaceous plants were found within the experimental polygon. At each site, the number of plant species varied from 11 to 31 (Table 1 ).

\section{Table 1}

Plant species number and phytoindicator estimation of the thermoregime

The phytoindication estimation of thermal climate was in the range 8.3-11.1 according to 23-points of the Didukh (2011) thermal climate scale. The phytoindication values can be converted to the value of the radiation balance. This rate can be estimated to be in the range of

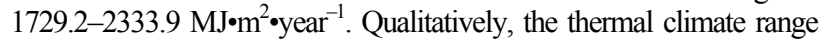
can be evaluated as favourable for plants in the range from sub-mesotherms to mesotherms.

In total, 257,437 invertebrate (Arthropoda and Mollusca) individuals of 6 classes, 13 orders, 50 families and 202 species or parataxonomic units were recorded. Diplopoda was most abundant taxonomic group, though it was represented only one species Rossiulus kessleri (Lohmander, 1927). This species took up $49.4 \%$ of the total community abundance. Coleoptera and Araneae were the considerably numerous taxonomic groups, which took up $22.4 \%$ and $18.2 \%$ of the total community abundance. These taxa were the most species-rich. Coleoptera was represented by 122 species and Araneae was represented by 67 species. 71 species among the investigated 202 species occurred 50 times or less.

The distribution of temperature weighted by species abundances is multimodal and can be presented as a mixture of two normal distributions (Kolmogorov-Smirnov d $=0.032, \mathrm{P}=0.98$ ). The temperature optimum has a 0.64 chance of following a distribution with a mean $17.1^{\circ} \mathrm{C}$ and variance 2.2. The chance is 0.36 that plant available moisture distribution has a mean $21.5^{\circ} \mathrm{C}$ and a variance 1.5 . Thus, the temperature optimum of in- 
vertebrates dwelling in the technosols varies in the range from 11.5 to $25.4^{\circ} \mathrm{C}$. The thermal range between the species optima is distributed unevenly. The distribution of species tolerance to temperature assessed on the basis of variance of the temperature weighted by species abundances has a normal distribution (Kolmogorov-Smirnov $\mathrm{d}=0.053, \mathrm{P}=0.59$ ). The analysis of distributions indicates the existence of two relatively homogeneous species groups in terms of thermal preferences : microtemperature and mesotemperature. This identification of groups is based on the phytoindicative estimates of thermoclimate which is in the range from microtemperature to mesotemperature conditions. There is a negative correlation $(r=-0.48, \mathrm{P}<0.001)$ between estimated species thermal optima and tolerance values. Thus, the microtemperature species are more tolerant to the thermal factor, and vice versa - the mesotemperature species are more sensitive. Probably, the high temperatures that occur within the studied area are close to the physiological limits of endurance of living organisms, as high temperatures act as a strong limiting factor.

The requirement of symmetry and bell-shaped response to the impact factor is necessary to use weighted average method for assessing the optimum and tolerance within a gradient of the temperature conditions. But it should be noted that this consideration does not always hold. It should be pointed out that the HOFJO-approach offers opportunities for species response modeling using more flexible models (Fig. 1).
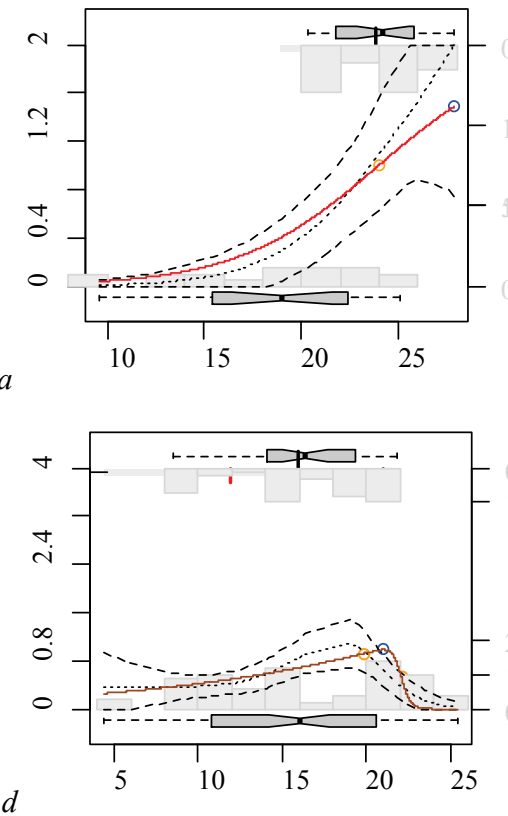

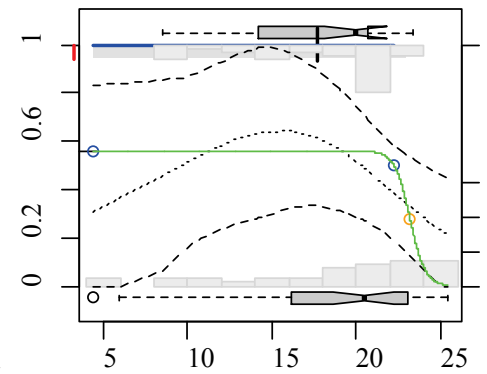

$b$

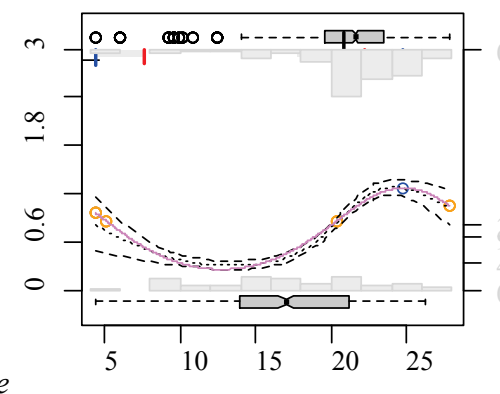

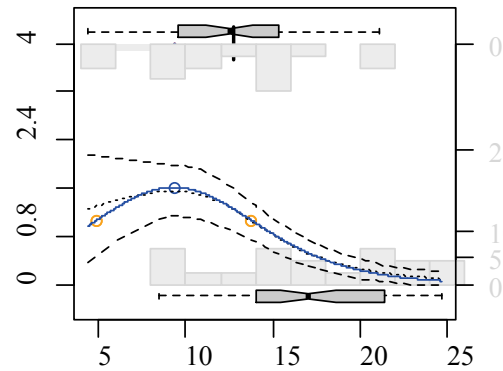

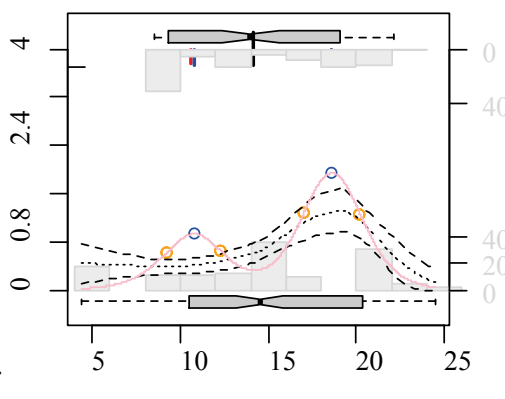

Fig. 1. The model diversity of species response to soil moisture gradient: $\mathrm{X}$-axis - the soil moisture presented as plant available moisture in $1 \mathrm{~m}$ soil layer (mm); Y-axis - the number of individuals; HOFJO-model: A - model II (Anoxia pilosa), B - model III (Asida lutosa), C - model IV (Galeruca tanaceti), D - model V (Haplodrassus bohemicus), E - model VI (Harpalus serripes),

$$
\text { F - model VII (Onthophagus vitulus) }
$$

The analysis showed that invertebrates' responses to the effect of temperature may be explained by all seven HOFJO models. The models V and VII have the most considerable ability to explain the species response patterns. The model VII is sensitive to the asymmetric bimodal response, and model $\mathrm{V}$ is sensitive to the asymmetric unimodal response. Thus, the vast majority of the invertebrates' responses to the temperature factor are asymmetric. Symmetrical models IV and VI apparently describe a fraction of invertebrate response patterns. Symmetrical responses provide an ideal situation, the impact of only the physical factor on the biological status of a species. In reality, there is a set of abiotic factors with simultaneously an important role of the biotic factors. Asymmetric unimodal response is most likely to be regarded as the result of the interaction of factors of an abiotic nature that violates perfect symmetry response to the impact of a single factor. Bimodality can be best explained by competitive exclusion of two or more species due to optimum overlap.

The procedures of the community ordination are usually sensitive to the pattern types of species response to the impact of environmental factors. One exception is the multidimensional scaling procedure (MDS) which is not sensitive to such restrictions. The stress is a goodness-of-fit measure of the multidimensional scaling procedure. This measure allows us to extract the appropriate number of the dimension. In the case where further increasing of the dimension number does not lead to a decrease in stress, one decides on the appropriate number of the dimension in the ordinate solution. In our case, with the value of stress 0.1 we have stopped on a solution of four dimensions. The nature of these dimensions can be interpreted by fitting environmental factors and MDS dimensions (Table 2).

The results of this procedure indicate that variation of the structure of the invertebrate community is due to meteorological factors, spatial and temporal variables, and also depends on the technosols' typological fea- tures. Moisture content in the soil is the most important factor of the community variation, as it determined $87 \%$ of variability in the structure of the complex. A group of species whose variation is described in dimension 1 is the most sensitive to the water content in technosols. It should be noted that the correlation of this dimension with air temperature is extremely insignificant. The temperature is capable of explaining $41 \%$ to $44 \%$ of variability in the community structure, indicating a second role among environmental factors that affect invertebrate fauna. The dimensions 2,3 and 4 are correlated with temperature.

\section{Discussion}

The problems of range, spacing, and nonlinearity are highly important in resolving the issue of the measurement of niche properties (Colwell \& Futuyma, 1971). The position and width are qualitative attributes of the niche (Gregory \& Gaston, 2000). The species niche parameters considerably depend on the mathematical constraints like model shape (Jansen \& Oksanen, 2013). The interaction with other environment factors is also important for the accurate estimation of the niche attributes. Thus, our results reveal that the nature of the effects of air temperature on the invertebrates' community structure is extremely complicated. The estimation of ecological complexity is increased, taking into account the influence of other meteorological factors, such as precipitation (mainly indicated by the dimensions 2 and 4), wind (indicated by the dimensions 2, 3 and 4), air humidity (indicated by the dimensions 2, 3 and 4), and atmospheric pressure (indicated by the dimensions 3 and 4). Our result is in agreement with concept that the intraspecific and interspecific interactions and environmental conditions affect niche position and niche width (Brown, 1999; Lawton, 1999). 
Table 2

Fitting environmental factors onto ordination dimensions

\begin{tabular}{|c|c|c|c|c|c|c|c|}
\hline Predictors & \multicolumn{4}{|c|}{ Dimensions } & $R^{2}$ & \multirow[t]{2}{*}{$\operatorname{Pr}(>r)$} & $\begin{array}{l}\text { Significance } \\
\text { codes } \\
\end{array}$ \\
\hline \multicolumn{7}{|c|}{ Climatic predictors } & \\
\hline $\begin{array}{l}\text { Precipitation, } \\
\mathrm{mm}\end{array}$ & -0.73 & -0.36 & -0.04 & -0.58 & 0.06 & 0.001 & *** \\
\hline $\begin{array}{l}\text { Wind speed, } \\
\mathrm{m} / \mathrm{s}\end{array}$ & -0.15 & 0.34 & 0.56 & -0.74 & 0.02 & 0.001 & *** \\
\hline $\mathrm{T}_{\min }$ & 0.07 & -0.82 & -0.34 & 0.46 & 0.40 & 0.001 & *** \\
\hline $\mathrm{T}_{\text {max }}$ & 0.04 & -0.69 & -0.41 & 0.59 & 0.41 & 0.001 & **** \\
\hline $\mathrm{T}$ & 0.07 & -0.76 & -0.38 & 0.53 & 0.44 & 0.001 & $* * *$ \\
\hline $\begin{array}{l}\text { Atmospheric } \\
\text { humidity, \% }\end{array}$ & -0.23 & 0.47 & 0.42 & -0.74 & 0.20 & 0.001 & $* * *$ \\
\hline $\begin{array}{l}\text { Atmospheric } \\
\text { pressure, gPa }\end{array}$ & 0.43 & 0.06 & 0.49 & -0.76 & 0.11 & 0.001 & **** \\
\hline $\mathrm{RAW}^{* * * * *}$ & -0.87 & 0.39 & -0.22 & 0.18 & 0.87 & 0.001 & **** \\
\hline \multicolumn{8}{|c|}{ Time predictors (AEM-variables, statistically significant predictors are shown only) } \\
\hline AEM_1 & 0.99 & -0.10 & 0.03 & 0.11 & 0.68 & 0.001 & $* * *$ \\
\hline $\mathrm{AEM}_{-}^{-2}$ & 0.04 & 0.78 & 0.39 & -0.48 & 0.37 & 0.001 & $* * *$ \\
\hline AEM_3 & -0.08 & -0.43 & 0.16 & -0.88 & 0.06 & 0.001 & $* * *$ \\
\hline AEM_4 & -0.29 & 0.81 & 0.27 & -0.43 & 0.03 & 0.001 & **** \\
\hline \multicolumn{8}{|c|}{$\begin{array}{c}\text { Spatial predictors (dbMEM-variables, } \\
\text { statistically significant predictors are shown only) }\end{array}$} \\
\hline Spat_1 & 0.01 & 0.00 & -0.55 & -0.84 & 0.46 & 0.001 & $* * *$ \\
\hline Spat_2 & -0.06 & -0.37 & 0.93 & 0.00 & 0.51 & 0.001 & \\
\hline Spat_3 & 0.01 & -0.53 & -0.12 & -0.84 & 0.03 & 0.001 & $* * *$ \\
\hline Spat_4 & 0.00 & -0.37 & 0.19 & -0.91 & 0.06 & 0.001 & *** \\
\hline Spat_5 & 0.02 & 0.31 & 0.67 & -0.67 & 0.07 & 0.001 & $* * *$ \\
\hline Spat_6 & -0.08 & 0.63 & 0.12 & 0.76 & 0.01 & 0.034 & $*$ \\
\hline Spat_7 & -0.07 & 0.02 & 0.89 & -0.46 & 0.01 & 0.014 & $*$ \\
\hline \multicolumn{8}{|c|}{ Technosols types, $R^{2}=0.12, \mathrm{P}<0.001$} \\
\hline$\overline{\mathrm{GG}}$ & 0.07 & 0.08 & -0.17 & 0.03 & - & - & - \\
\hline LL & 0.01 & 0.01 & -0.14 & -0.09 & - & - & - \\
\hline PZ & -0.01 & 0.06 & 0.08 & 0.12 & - & - & - \\
\hline RB & 0.02 & 0.00 & -0.06 & -0.06 & - & - & - \\
\hline TM & -0.05 & -0.11 & 0.25 & 0.05 & - & - & - \\
\hline
\end{tabular}

Note: significance codes: $* * *-<0.001 ; * *-<0.01 ; *_{-}<0.05 ; * * * *$ readily available water content $(\mathrm{mm}) ; \mathrm{GG}$ - green-grey clay, LL - loess-like loam, PZ - humus-rich $70 \mathrm{~cm}$ top soil layer formed on loess-like loam, RB Red-brown clay, TM - technological mixture of rocks.

Animal community dynamic induced by reclamation is affected by plant cover and by abiotic regimes (Hendrychova, 2008; Buchori et al., 2018). The coherent dynamic of the invertebrate population was reflected by means of NMDS ordination approach. Community decomposition into NMDS-dimensions may be discussed in terms of structural and process context (La Notte et al., 2017). NMDS-dimensions can be processed over a range of spatial and temporal scales (Allen et al., 2014). Our results revealed that the dimensions obtained after NMDSprocedure were confirmed as being subject to certain time trends, which is indicated by the correlation with AEM-time variables. The AEM-1 variable simulates a monotonous sigmoidal trend, which correlates to the dimension 1. A gradual reduction of the soil water content during the year is quite good in compliance with this tendency, which cannot be said about the temperature. The dimensions $2-4$ indicating the temperature dependent dynamics of the community correlate with AEMvariables $2-4$. This result shows the fine-scale components in the variation of these dimensions. This also demonstrates that the temperature variability during the season is subject to certain regular patterns, which could affect the animals' adaptation and produce the appropriate phenological rhythms. The species following evolution demonstrated ability for adaptation only to the recurring environmental variation caused by geophysical cycles such as temperature and precipitation (Foster \& Kreitzman, 2009). Therefore, in the case of structured temperature patterns in time, it is formally impossible to say whether the temperature really affects living organisms, or acts just the same as the rhythm of biological and temperature processes due to common synchronization with the third factor. As the results indicate, coincidence of the dynamics of temperature processes and dynamics of the community structure is very important. The time variables are able to explain $3-68 \%$ variation of the community structure. Obviously, the role of the temporal component of the community variation should be previously extracted to assess the real role of temperature as the ecological factor. Phenology is discussed as the temporal aspect of natural history (Forrest \& MillerRushing, 2010), that is why we interpret the temporal component of the variability as a natural course of phenological processes, the rhythm of which is guided by certain stimuli.

The spatial structuring of the community dynamics may be revealed by correlation of dimensions with dbMEM spatial variables. The understanding of the factors underlying observed spatial and temporal patterns and different scales is important for prediction of the community behaviour (Levin, 1992). In our investigation, spatial variables were found to explain $1-51 \%$ of variation of the community structure. The importance of the spatial variables was reduced as the spatial process frequency increases (indicated by the sequence number of variables). It should be noted that the dimension 1 reflects the site-non-specific processes, universal for the entire territory as a whole. Dimensions 3 and 4, which, as appropriate, are closely related to the temperature regime, are significantly spatially structured. Spatial structuring may be a result of processes of neutral nature (Zhukov et al., 2019) or a result of the influence of spatial structured properties of the environment (Karunaratne et al., 2015). The latter may be associated with the spatial heterogeneity of the technosols' distribution. In this result it can be assumed that the impact of temperature factors on invertebrate fauna depends on the characteristics of vegetation and soil. Thus, the influence of spatial factors on these processes should be extracted to assess the purely temperature component in the variation of the animal community and population.

The spatial allocation of the technosols can also be the cause of spatial structured variation of the animal community. In addition, technosols can have a specific significance in the variability of the environmental conditions and processes. The techonosol types generally define $12 \%$ of the variation in the invertebrate fauna. It is impossible to exclude the possibility that artificial soils that differ in their primary stratigraphy and the properties of rocks of which they are formed during half a century of the pedogenesis gain convergent similar properties, resulting in differences between them becoming less apparent. Thus, the role of the technosol types in the invertebrate community dynamics should also be extracted to determine the role of temperature for animals.

\section{Conclusion}

The most important environmental factor following soil moisture affecting invertebrates in the technosols is temperature. Temperature optimum for invertebrates dwelling in technosols varies in the range of 11.5 to $25.4^{\circ} \mathrm{C}$. From the total set of the invertebrates, the two relatively homogeneous groups in relation to thermal preferences of species were extracted: the microtemperature and mesotemperature groups. The microtemperature species are more tolerant to the thermal factor, and the mesotemperature species are more sensitive. The invertebrates' response to the effect of temperature can be approximated by the seven HOFJO models. The models V and VII most often have the higher explanatory ability to describe the species response to temperature gradient. The effect of temperature on the structure of invertebrate communities is complex and depends on other meteorological factors such as precipitation, wind, humidity and atmospheric pressure. The real values of the invertebrates' temperature optima and tolerance may be assessed only after extraction of the effect of the other environmental, spatial and temporal variables.

The authors are grateful to Paul Bradbeer for checking the English text and the two anonymous reviewers for helping us to improve earlier versions of this paper.

\section{References}

Allen, C. R., Angeler, D. G., Garmestani, A. S., Gunderson, L. H., \& Holling, C. S. (2014). Panarchy: Theory and application. Ecosystems, 17(4), 578-589. Austin, M. P. (1976). On non-linear species response models in ordination. Vegetatio, 33(1), 33-41. 
Austin, M. P. (1999). A silent clash of paradigms: Some inconsistencies in community ecology. Oikos, 86(1), 170-178.

Austin, M. P. (2013). Vegetation and environment: Discontinuities and continuities. In: van der Maarel, E., \& Franklin, J. (Ed.). Vegetation ecology. Second Edition. John Wiley \& Sons, Ltd. Pp. 52-84.

Baho, D. L., Futter, M. N., Johnson, R. K., \& Angeler, D. G. (2015). Assessing temporal scales and patterns in time series: Comparing methods based on redundancy analysis. Ecological Complexity, 22, 162-168.

Beck, J., \& Kitching, I. J. (2007). Correlates of range size and dispersal ability: A comparative analysis of sphingid moths from the Indo-Austalian tropics. Global Ecology and Biogeography, 16, 341-349.

Bonsall, M. B., \& Hastings, A. (2004). Demographic and environmental stochasticity in predator - prey metapopulation dynamics. Journal of Animal Ecology, 73, 1043-1055.

Bonte, D., Baert, L., \& Maelfait, J.-P. (2002). Spider assemblage structure and stability in a heterogenous coastal dune system (Belgium). Journal of Arachnology, 30, 331-343

Borcard, D., \& Legendre, P. (2002). All-scale spatial analysis of ecological data by means of principal coordinates of neighbour matrices. Ecological Modelling, 153, 51-68.

Borcard, D., Legendre, P., Avois-Jacquet, C., \& Tuosimoto, H. (2004). Dissecting the spatial structure of ecological data at multiple scales. Ecology, 85, 1826-1832.

Brandle, M., Durka, W., Krug, H., \& Brandl, R. (2003). The assembly of local communities: Plants and birds in non-reclaimed mining sites. Ecography, 26, 652-660.

Brandle, M., Ohlschlager, S., \& Brandl, R. (2002). Range size in butterflies: Correlation across scales. Evolutionary Ecology Research, 4, 993-1004.

Brown, J. H. (1999). Macroecology: Progress and prospect. Oikos, 87, 3-14.

Brygadyrenko, V. V. (2016). Influence of litter thickness on the structure of litter macrofauna of deciduous forests of Ukraine's steppe zone. Visnyk of Dnipropetrovsk University. Biology, Ecology, 24(1), 240-248.

Buchholz, S. (2009). Community structure of spiders in coastal habitats of a Mediterranean delta region (Nestos Delta, NE Greece). Animal Biodiversity and Conservation, 32(2), 101-115.

Buchori, D., Rizali, A., Rahayu, G. A., \& Mansur, I. (2018). Insect diversity in post-mining areas: Investigating their potential role as bioindicator of reclamation success. Biodiversitas, 19, 1696-1702.

Burnham, K. P., \& Anderson, D. R. (2002). Model selection and multi-model inference: A practical information-theoretic approach. Springer, Berlin.

Buzuk, G. N. (2017). Phytoindication with ecological scales and regression analysis: Environmental index. Bulletin of Pharmacy, 76, 31-37.

Colwell, R. K., \& Futuyma, D. J. (1971). Measurement of niche breadth and overlap. Ecology, 52, 567-576.

David, J. F., \& Handa, I. T. (2010). The ecology of saprophagous macroarthropods (millipedes, woodlice) in the context of global change. Biological Reviews, 85(4), 881-895.

Desender, K., Ervinck, A., \& Tack, G. (1999). Beetle diversity and historical ecology of woodlands in Flanders. Belgian Journal of Zoology, 129(1), 139-155.

Devictor, V., Clavel, J., Julliard, R., Lavergne, S., Mouillot, D., Thuiller, W. Venail, P., Villéger, S., \& Mouquet, N. (2010). Defining and measuring ecological specialization. Journal of Applied Ecology, 47, 15-25.

Didukh, Y. P. (2011). The ecological scales for the species of Ukrainian flora and their use in synphytoindication. Phytosociocentre, Kyiv.

Dray, S., Legendre, P., \& Peres-Neto, P. (2006). Spatial modelling: A comprehensive framework for principal coordinate analysis of neighbours matrices (PCNM). Ecological Modelling, 196, 483-493.

Dray, S., Pélissier, R., Couteron, P., Fortin, M.-J., Legendre, P., Peres-Neto, P. R., Bellier, E., Bivand, R., Blanchet, F. G., De Cáceres, M., Dufour, A.-B., Heegaard, E., Jombart, T., Munoz, F., Oksanen, J., Thioulouse, J., \& Wagner, H. H. (2012). Community ecology in the age of multivariate multiscale spatial analysis. Ecological Monographs, 82, 257-275.

Elton, C. (1927). Animal Ecology. Sidgwick and Jackson, London.

Forrest, J., \& Miller-Rushing, A. J. (2010). Toward a synthetic understanding of the role of phenology in ecology and evolution. Philosophical Transactions of the Royal Society B: Biological Sciences, 365(1555), 3101-3112.

Foster, R. G., \& Kreitzman, L. (2009). Seasons of life: The biological rhythms that enable living things to thrive and survive. Yale University Press, New Haven.

Gallé, R., Vesztergom, N., \& Somogyi, T. (2011). Environmental conditions affecting spiders in grasslands at the lower reach of the River Tisza in Hungary. Entomologica Fennica, 22, 29-38.

Ge, B., Daizhen, Z., Jun, C., Huabin, Z., Chunlin, Z., \& Boping, T. (2014). Biodiversity variations of soil macrofauna communitiesin forestsina reclaimed coastwith different diked history. Pakistan Journal of Zoology, 46(4), 1053-1059.

Gerlach, J., Samways, M., \& Pryke, J. (2013). Terrestrial invertebrates as bioindicators: An overview of available taxonomic groups. Journal of Insect Conservation, 17(4), 831-850
Gregory, R. D., \& Gaston, K. J. (2000). Explanations of commonness and rarity in British breeding birds: Separating resource use and resource availability. Oikos, $88,515-526$

Grinnell, J. (1917). The niche relationship of the California Thrasher. The Auk, 34(4), 427-433.

Hendrychova, M. (2008). Reclamation success in post-mining landscapes in the Czech Republic: A review of pedological and biological studies. Journal of Landscape Studies, 1, 63-78.

Hendrychova, M., Salek, M., Tajovsky, K, \& Reho, M. (2011). Soil properties and species richness of invertebrates on afforested sites after brown coal mining. Restoration Ecology, 20(5), 561-567.

Hering, R., Hauptfleisch, M., Geißler, K., Marquart, A., Schoenen, M., \& Blaum, N. (2019). Shrub encroachment is not always land degradation: Insights from ground-dwelling beetle species niches along a shrub cover gradient in a semiarid Namibian savanna. Land Degradation and Devilopment, 30(1), 14-24.

Hildmann, E., \& Wunsche, M. (1996). Lignite mining and its after-effects on the central German landscape. Water, Air and Soil Pollution, 91, 79-87.

Hodecek, J., Kuras, T., Sipos, J., \& Dolny, A. (2016). Role of reclamation in the formation of functional structure of beetle communities: A different approach to restoration. Ecological Engineering, 94, 537-544.

Hodecek, J., Kuras, T., Sipos, J., \& Dolny, A. (2015). Post-industrial areas as successional habitats: Long-term changes of functional diversity in beetle communities. Basic and Applied Ecology, 16(7), 629-640.

Huisman, J., Olff, H., \& Fresco, L. F. M. (1993). A hierarchical set of models for species response analysis. Journal of Vegetation Science, 4(1), 37-46.

Hutchinson, G. E. (1957). Concluding remarks. Cold Spring Harbour Symposium on Quantitative Biology, 22, 415-427.

Jamil, T., \& ter Braak, C. J. F. (2013). Generalized linear mixed models can detect unimodal species-environment relationships. PeerJ, 1, e95.

Jansen, F., \& Oksanen, J. (2013). How to model species responses along ecological gradients - Huisman - Olff - Fresco models revisited. Journal of Vegetation Science, 24, 1108-1117.

Karunaratne, S., Singh, B., Robinson, L., Campbell, C., Yao, H., \& Powell, J. (2015). Deterministic processes vary during community assembly for ecologically dissimilar taxa. Nature Communications, 6(1), 1-10.

Klimkina, I., Kharytonov, M., \& Zhukov, O. (2018). Trend analysis of watersoluble salts vertical migration in technogenic edaphotops of reclaimed mine dumps in Western Donbass (Ukraine). Journal of Environmental Research, Engineering and Management, 74(2), 82-93.

Knapp, M., Seidl, M., Knappová, J., Macek, M., \& Saska, P. (2019). Temporal changes in the spatial distribution of carabid beetles around arable fieldwoodlot boundaries. Scientific Reports, 9(1), 8967.

Konstantinov, A. S., Korotyaev, B. A., \& Volkovitsh, M. G. (2009). Insect biodiversity in the Palearctic region. In: Foottit, R., \& Adler, P. (Eds.). Insect biodiversity: Science and society. Blackwell Publisher, Chinchester. Pp. 107-162.

Kunah, O. M., Zelenko, Y. V., Fedushko, M. P., Babchenko, A. V., Sirovatko, V. O., \& Zhukov, O. V. (2019). The temporal dynamics of readily available soil moisture for plants in the technosols of the Nikopol Manganese Ore Basin. Biosystems Diversity, 27(2), 156-162.

Kunakh, O. N., Kramarenko, S. S., Zhukov, A. V., Zadorozhnaya, G. A., \& Kramarenko, A. S. (2018). Intra-population spatial structure of the land snail Vallonia pulchella (Müller, 1774) (Gastropoda; Pulmonata; Valloniidae). Ruthenica, 28(3), 91-99.

La Notte, A., D'Amato, D., Mäkinen, H., Paracchini, M. L., Liquete, C., Egoh, B., Geneletti, D., \& Crossman, N. D. (2017). Ecosystem services classification: A systems ecology perspective of the cascade framework. Ecological Indicators, 74, 392-402.

Laporta, G. Z., \& Sallum, M. A. M. (2014). Coexistence mechanisms at multiple scales in mosquito assemblages. BMC Ecology, 14(1), 30.

Lavelle, P., Bignell, D., Lepage, M., Wolters, V., Roger, P., Ineson, P., Heal, O. W., \& Dhillion, S. (1997). Soil function in a changing world: The role of invertebrate ecosystem engineers. European Journal of Soil Science, 33, 159-193.

Lawton, J. H. (1999). Are there general laws in ecology? Oikos, 84, 177-192.

Legendre, P., \& Gallagher, E. D. (2001). Ecologically meaningful transformations for ordination of species. Oecologia, 129(2), 271-280.

Levin, S. A. (1992). The problem of pattern and scale in ecology. Ecology, 73, 1943-1967.

Liu, J.-L., Li, F.-R., Sun, T.-S., Ma, L.-F., Liu, L.-L., \& Yang, K. (2016). Interactive effects of vegetation and soil determine the composition and diversity of Carabid and Tenebrionid functional groups in an arid ecosystem. Journal of Arid Environments, 128, 80-90.

Mallis, R. E., \& Hurd, L. E. (2005). Diversity among ground dwelling spider assemblages: Habitat generalists and specialists. Journal of Arachnology, 33, 101-109.

Marc, P., Canard, A., \& Ysnel, F. (1999). Spiders (Araneae) useful for pest limitation and bioindication. Agriculture, Ecosystems and Environment, 74, 229-273.

Michaelis, J., \& Diekmann, M. R. (2017). Biased niches - Species response curves and niche attributes from Huisman - Olff - Fresco models change with differing species prevalence and frequency. PLoS One, 12(8), e0183152. 
Nash, K. L., Allen, C. R., Angeler, D. G., Barichievy, C., Eason, T., Garmestani, A. S., Graham, N. A. J., Granholm, D., Knutson, M., Nelson, R. J., Nystrom, M., Stow, C. A., \& Sundstrom, S. M. (2014). Discontinuities, cross-scale patterns, and the organization of ecosystems. Ecology, 95, 654-667.

Oksanen, J. (2004). Multivariate analysis in ecology. Lecture Notes. Department of Biology, Universityof Oulu.

Oksanen, J., Blanchet, F. G., Kindt, R., Legendre, P., Minchin, P. R., O'Hara, R. B., Simpson, G. L., Solymos, P., Stevens, M. H. H., \& Wagner, H. (2018). Community Ecology Package. R package version 2.5-2.

Pakhomov, O., Kulbachko, Y., Didur, O., \& Loza, I. (2008). Mining dump rehabilitation: The potential role of bigeminate-legged millipeds (Diplopoda) and artificial mixed-soil habitats. In: Apostol, I., Barry, D. L., Coldewey, W. G., \& Reimer, D. W. G. (Eds.). Optimisation of disaster forecasting and prevention measures in the context of human and social dynamics. NATO science for peace and security series E-human and societal dynamics. Chisinau, Moldova, 52, 163 171.

Paoletti, M. G., \& Hassall, M. (1999). Woodlice (Isopoda: Oniscidea): Their potential for assessing sustainability and use as bioindicators. Agriculture, Ecosystems and Environment, 74, 157-165.

Paoletti, M. G., Osler, G. H. R., Kinnear, A., Black, D. J., Thomson, L. J., Tsitsilas, A., Sharley, D., Judd, S., Neville, P., \& D'inca, A. (2007). Detritivores as indicators of landscape stress and soil degradation. Australian Journal of Experimental Agriculture, 47(4), 412-423.

Pontegnie, M., du Bus de Warnaffe, G., \& Lebruna, P. (2005). Impacts of silvicultural practices on the structure of hemi-edaphic macrofauna community. Pedobiologia, 49(3), 199-210.

Rao, C. R. (1995). A review of canonical coordinates and an alternative to correspondence analysis using Hellinger distance. Qüestiió, 19, 23-63.

Rehor, M., Lang, T., \& Eis, M. (2006). Application of new methods in solving current reclamation issues of Severoceske doly, a.s. localities. World of Surface Mining, 6, 383-386.

Rushton, S. P., \& Eyre, M. D. (1992). Grassland spider habitats in North-East England. Journal of Biogeography, 19, 99-108.

Schoener, T. W. (1974). The compression hypothesis and temporal resource partitioning. Proceedings of the National Academy of Sciences, 71(10), 4169-4172.

Sklenicka, P., Prikryl, I., Svoboda, I., \& Lhota, T. (2004). Non-productive principles of landscape rehabilitation after long-term opencast mining in north-west Bohemia. Journal of the South African Institute of Mining and Metallurgy, $104,83-88$.
Šmilauer, P., \& Lepš, J. (2014). Multivariate analysis of ecological data using CANOCO 5. Cambridge: Cambridge University Press.

Soberon, J. (2007). Grinnellian and Eltonian niches and geographic distributions of species. Ecology Letters, 10(12), 1115-1123.

Sokolov, S. G., \& Zhukov, A. V. (2017). Functional diversity of a parasite assemblages of the Chinese sleeper Perccottus glenii Dybowski, 1877 (Actinopterygii: Odontobutidae) and habitat structure of the host. Biology Bulletin, 44(3), 331-336.

Souty-Grosset, C., Badenhausser, I., Reynolds, J. D., \& Morel, A. (2005). Investigations on the potential of woodlice as bioindicators of grassland habitat quality. European Journal of Soil Biology, 41(3), 109-116.

Szczepanska, J., \& Twardowska, I. (1999). Distribution and environmental impact of coal-mining wastes in Upper Silesia Poland. Environmental Geology, 38, 249-258.

Tokeshi, M. (1999). Species coexistence: Ecological and evolutionary perspectives. Blackwell Science, London.

Warburg, M. R., Linsenmair, K. E., \& Bercovitz, K. (1984). The effect of climate on the distribution and abundance of isopods. Symposia of the Zoological Society of London, 53, 339-367.

Westhoff, V., \& van der Maarel, E. (1978). The Braun-Blanquet approach. In: Whittaker, R. H. (Ed.). Classification of plant communities. Pp. 289-399.

Wise, D. H. (1993). Spiders in ecological webs. Cambridge University Press, Cambridge.

Yorkina, N., Maslikova, K., Kunah, O., \& Zhukov, O. (2018). Analysis of the spatial organization of Vallonia pulchella (Muller, 1774) ecological niche in technosols (Nikopol Manganese Ore Basin, Ukraine). Ecologica Montenegrina, 17, 29-45.

Yorkina, N., Zhukov, O., \& Chromysheva, O. (2019). Potential possibilities of soil mesofauna usage for biodiagnostics of soil contamination by heavy metals. Ekológia (Bratislava), 38(1), 1-10.

Zadorozhnaya, G. A., Andrusevych, K. V., \& Zhukov, O. V. (2018). Soil heterogeneity after recultivation: Ecological aspect. Folia Oecologica, 45(1), 46-52.

Zhukov, O., Kunah, O., Dubinina, Y., \& Novikova, V. (2018). The role of edaphic and vegetation factors in structuring beta diversity of the soil macrofauna community of the Dnipro river arena terrace. Ekológia (Bratislava), 37(3), 301-327.

Zhukov, O., Kunah, O., Dubinina, Y., Zhukova, Y., \& Ganga, D. (2019). The effect of soil on spatial variation of the herbaceous layer modulated by overstorey in an Eastern European poplar-willow forest. Ekológia (Bratislava), 38(3), 353-372. 